\title{
Exocrine and Endocrine Pancreatic Cancer pTis TNM Finding v7
}

National Cancer Institute

\section{Source}

National Cancer Institute. Exocrine and Endocrine Pancreatic Cancer PT is TNM Finding

v7. NCl Thesaurus. Code C90289.

Exocrine or endocrine pancreatic cancer with a finding of carcinoma in situ. This also

includes the Panln III classification. (from AJCC 7th Ed.) 